\title{
Clinical intuition: more than rational?
}

\author{
Glyn Brokensha, Senior Lecturer, Medical Education Unit, University of \\ Adelaide, Adelaide
}

\section{SYNOPSIS}

Clinical intuition is controversial, not least because of a confusion of definition. Excluding mysticism, three categories of intuition are identified; the spurious, the inferential and the holistic. Intuition is located in the understanding that the patient is much more than the disease. To question our assumptions about how the evidence-base informs our decisions, rehabilitates intuition and recovers reason from rationalisation.

Index words: decision-making, consumers.

(Aust Prescr 2002;25:14-5)

\section{Introduction}

'Intuition is a sacred gift. Rationality its faithful servant.' 1 Why, in the full flow of an epidemic of gastroenteritis, did I choose to admit that child for a lumbar puncture? There were so many others, apparently just the same.

Why, at the end of an exhausting day, did I ask the mother of that child with feeding difficulties to bring him in? He had only recently had a normal six-week examination. Why, having found nothing remarkable in my examination did I unaccountably send him immediately to our base hospital?

The first baby had viral meningitis, the second an undiagnosed coarctation of the aorta. In both instances I had a bad case of grateful bewilderment!

'Clinical intuition', the sages nod, as if such categorisation revealed more than it actually conceals. Naming a process brings such comfort to our ignorance of it.

\section{What is intuition?}

Many clinicians would agree that intuition plays a part in diagnosis and management, although few would concur on how much. What exactly do we mean by clinical intuition? The scarce literature is blighted by confusion even over definition. $^{2}$

Intuition seems to be used mainly in four senses:

- mystical

- spurious

- inferential

- holistic.

\section{Mysticism}

Mystical intuition refers to the notion that there are forces at work which have no rational explanation. By some direct means, the intuiter is influenced in ways that are inexplicable either by introspection or by empirical research.
In other words, my clinical intuitions in respect of the two babies were the result of something occurring in me which neither I nor scientific inquiry can understand. A mystical transmission of information, as if by 'the hand of God'.

\section{Spurious}

Spurious intuition argues that we often act illogically. When our questionable actions are vindicated we egocentrically attribute the success to ourselves, calling it 'intuition'. When events prove otherwise, we rationalise our mistake and repress self-doubt, preferring denial to the painful reality of imperfection.

In other words, my two decisions were elevated post-facto to shining successes. Many other clinical blunders were ignored and repressed.

\section{Inferential}

Inferential intuition recognises that much more sensory information impinges upon us than can ever be comprehended. These sensory impressions could be unconsciously integrated and form the basis for intuitive judgment and action.

'A judgment in which visual and verbal cues are so rapidly and subliminally observed that their contributions to the final decision are virtually forgotten.' ${ }^{3}$

In other words, my clinical intuitions were as a result of sensory factors such as the smell of the house, the appearance of each baby or the demeanour of the parents. Sadly for my place in the Diagnostician's Hall of Fame, I will only ever be sketchily aware of what these factors were.

\section{Holism}

Holistic intuition supposes that in our 'modelling' of the world, we can be unconsciously influenced by gaps, redundancies and hidden connections in the data. Unobserved, they influence our thinking and impact upon our decisions.

'Where gaps, missing pieces, or hidden relationships are detected within ... the whole array of perceptual information' ${ }^{3}$ In other words, my diagnostic acumen was unknowingly built on an unconscious 'modelling', not only of the clinical presentation, but also of the prevailing social milieu and even of the process of being a general practitioner. Presumably these 'models' are built through time spent in the discipline, which is why intuition has been traditionally regarded as the preserve of the expert. ${ }^{3}$

That such processing could occur out of awareness is unsurprising given our extraordinary sensory capacity and the computational immensity of our neurology. Indeed, there is rational evidence to support such an intuitive view of intuition. ${ }^{2}$ An elegant psychological experiment demonstrated the unconscious development and use of intuition. Volunteers played a gambling game which 'simulates real life 
decision-making in the way it factors uncertainty, rewards and penalties'. They quickly developed and utilised advantageous strategies without realising. 'Moreover, they began to develop anticipatory skin conductance responses whenever they pondered a choice that turned out to be risky, before they knew explicitly that it was a risky choice. ${ }^{4}$

\section{Controversial or contrary?}

The persistent controversy about clinical intuition is unsurprising, given our empiricist traditions. However, a wealth of rational evidence attests to the prevalence of intuitive thinking in clinical situations and much evidence also points to its practicality. 2,5

Unfortunately, the evidence often muddles the many meanings of intuition and confuses rather than clarifies. Intuition occurs in the context of discovery. Once the existence of an intuition has been noticed, entirely different strategies are required to evaluate the content of the intuition. 'The largely unconscious process involved in generating hunches is quite different from the conscious processes required to test them'. ${ }^{6}$

In other words the objective validity of intuitions, in terms of whether they work out to be true or not, is an irrelevancy. The value of an intuition lies not in its accuracy, but in its ability to intrude itself into consciousness.

There is also a widespread and mistaken notion that intuition is necessarily irrational. An 'esoteric talent available only to a few initiates ${ }^{7}$, 'that gifted minority' ${ }^{9}$ and 'not legitimate knowledge'. 3 This notion is itself irrational, based on a 'belief that intuition is an irrational process ... as a consequence it is assumed that intuition can neither be fully understood nor explained'. ${ }^{2}$

Although by definition irrational to the intuiter, intuition is evidently a process capable of rational investigation and explication. It seems that in evaluating intuition, we are often not rational.

\section{A certain uncertainty}

It seems that our quest for certainty, to have the 'right answers', has often caused us to ask the wrong questions. Clinical trials, the source of evidence-based medicine, are often unhelpful, because they pose the wrong questions. ${ }^{9}$

Our disease-centred view causes us to lose sight of the person. 'Information scientists are keen to know [the] information [that] physicians would like to have available when they tackle clinical decisions. The results of their studies are intriguing, yet ultimately predictable: physicians want information that is relevant to specific questions about specific patients.' ${ }^{9}$

'Mrs Jones may have an illness but she also has a predicament.' It is an individual predicament, which reminds us that we too have an individual predicament: what are we to do now?

We fail Mrs Jones, by clinging mindlessly to evidence-based medicine without '... understanding the limits of generalisability in our clinical experience and in the research we read. ${ }^{10}$ Without such understanding, our evidence becomes orthodoxy and our practice a religion.

So, how are we to respond to Mrs Jones' individual situation? Maybe by following the advice to think more and perhaps read less. ${ }^{9}$
'The process of questioning our claims and assumptions in clinical decision-making is part of a recent interpretive turn in medicine, one that stands in opposition to evidence-based medicine ... Being a good physician involves far more than an appeal to best evidence. ... A reliance on evidence alone forces us to stop too soon in our clinical reasoning. ${ }^{10}$

\section{The wealth of experience}

Appreciable evidence ${ }^{2,3,5}$ now supports the view that useful clinical intuition, far from being an 'esoteric talent', is directly related to knowledge and experience and that ' $\ldots$ it is particularised knowledge that plays a vital role for experts, not inexplicable powers of intuition' ${ }^{11}$

When we learn to ride a bicycle, drive a car or play a musical instrument we develop a practical expertise. Initially, our attention is narrowed and focused on the task. We quickly become fatigued. Later, as our competence grows, we become increasingly capable and can attend to the wider sensory environment.

This is the context of the expert practitioner's intuition. 'Complex sequences of actions can become so routine through practice and experience that they are carried out semiautomatically ... while perceptual awareness of other, possibly unusual aspects of the situation increases.' ${ }^{2}$

Most patients have a wealth of this experience too. This is not generally in the domains of clinical knowledge and skill, but in their own experience they are, de facto, experts!

Patients' intuitions about their own health are usually ignored, often discounted and occasionally denigrated, despite evidence that attention to them at the very least improves our own clinical intuition. ${ }^{5}$ The rational, empathic, compassionate physician, the clinician to whom the individual's experience of illness is paramount, intuitively appreciates the uniqueness of the patient, the situation, and the doctor.

Clinical intuitions then, are the consequences of a particular clinician, engaged with a particular patient in a particular place. As such, we recognise that intuition is much more than rational, it is reasonable.

\section{E-mail: glyn.brokensha@adelaide.edu.au}

\section{REFERENCES}

1. Einstein A, quoted in: Hassed C. Knowledge and intuition. Aust Fam Physician 1999;28:505-6.

2. Easen $P$, Wilcockson $J$. Intuition and rational decision-making in professional thinking: a false dichotomy? J Adv Nurs 1996;24:667-73.

3. Cioffi J. Heuristics, servants to intuition, in clinical decision-making. J Adv Nurs 1997;26:203-8.

4. Bechara A, Damasio H, Tranel D, Damasio AR. Deciding advantageously before knowing the advantageous strategy. Science 1997;275:1293-5.

5. King L, Appleton JV. Intuition: a critical review of the research and rhetoric. J Adv Nurs 1997;26:194-202.

6. Bowers KS, Regehr G, Balthazard C. Intuition in the context of discovery. Cognit Psychol 1990;22:72.

7. English I. Intuition as a function of the expert nurse: a critique of Benner's novice to expert model. J Adv Nurs 1993;18:387-93.

8. Benderley BL. Every day intuition. Psychol Today 1989;23:35-40.

9. Hoey J. The one and only Mrs. Jones. CMAJ 1998;159:241-2.

10. Horton R. The grammar of interpretive medicine. CMAJ 1998;159:245-9.

11. Gott SP. Technical intuition in system diagnosis, or accessing the libraries of the mind. Aviat Space Environ Med 1988;59(II Suppl):A59-64.

Conflict of interest: none declared 